\title{
The immunobiology of Leishmania braziliensis infection
}

\section{Camila I. de Oliveira ${ }^{1,2 *}$ and Claudia I. Brodskyn ${ }^{1,2 *}$}

${ }^{1}$ Centro de Pesquisas Gonçalo Moniz, FIOCRUZ, Salvador, Bahia, Brazil

2 Instituto de Investigação em Imunologia, Salvador, Bahia, Brazil

Edited by:

Nathan Peters, National Institute of

Allergy and Infectious Diseases, USA

Reviewed by:

Dina Weilhammer, Lawrence

Livermore National Lab, USA

Wendy Sammons-Jackson, United

States Army Medical Research

Institute of Infectious Diseases, USA

Ricardo T. Gazzinelli, University of

Massachusetts Medical School, USA

${ }^{*}$ Correspondence:

Camila I. de Oliveira and Claudia I.

Brodskyn, Centro de Pesquisas

Gonçalo Moniz, CPqGM-FIOCRUZ,

Rua Waldemar Falcão, 121 Salvador,

Bahia, Brazil. e-mail:

camila@bahia.fiocruz.br;

brodskyn@bahia.fiocruz.br
Leishmaniases are a group of diseases caused by protozoa of the genus Leishmania that affect millions of people worldwide. These diseases are caused by distinct Leishmania species, of which L. braziliensis, a NewWorld representative of the Leishmania genus, has been the least studied. Although leishmaniasis caused by $L$. braziliensis induces a range of clinical manifestations ranging from mild localized lesions to severe mucosal involvement, few studies have focused on elucidating the immune mechanisms behind this pathology. In this review, we focus on the immunobiology of L. braziliensis infection, emphasizing the innate and adaptive immune responses and taking into consideration both studies performed in endemic areas and experimental models of infection. Additionally, we address recent findings regarding the role of sand fly saliva in disease immunopathogenesis and vaccine development.

Keywords: Leishmania braziliensis, innate immunity, human adaptive immunology, animal models

\section{INFECTION WITH NEW WORLD LEISHMANIA SPECIES: CLINICAL ASPECTS}

Rebelo etal. (2010) proposed the term tegumentary (skin or mucosal) leishmaniasis (TL) to the French Society of Dermatology in 1925, the first contribution of Brazilian researchers to the study of this disease. TL is a major health problem in Brazil, where the main Leishmania species associated with this disease are Leishmania (Viannia) braziliensis, L. (V.) naiffi, L. (V.) shawi, L. (V.) lainsoni, and L. (Leishmania) amazonensis. Of these, L. braziliensis is the predominant species in the regions of Brazil where TL is endemic, and it occurs in areas of both ancient and recent colonization with a low prevalence in the Amazonas state (Jones et al., 1987). L. braziliensis transmission is associated with the presence of domestic animals, which are implicated as potential reservoirs. It is transmitted by several different sand fly species, including Lutzomyia intermedia, Lu. whitmani, and $L u$. wellcomei (Miranda etal., 2002; Rebelo et al., 2010). L. amazonensis has been identified in different areas of Brazil and induces cutaneous ulcers, including diffuse cutaneous leishmaniasis. The main reservoirs for L. amazonensis are rodents and marsupials, and the main vector species associated with its transmission are Lu. flaviscutellata and Lu. olmeca. Host-parasite interactions can lead to a series of events culminating in clinical manifestations; the clinical forms of TL vary due to this complexity. In Brazil, TL can present as a single lesion (LCL, localized cutaneous leishmaniasis) that can be unapparent or discrete and can spontaneously heal. Multiple ulcerations may be present, compromising the mucosal areas (ML, mucosal leishmaniasis). ML is particularly important in South America and is caused primarily by L. braziliensis, although $L$. amazonensis has also been implicated (Costa et al., 1986). ML is characterized by latency and chronicity. Parasitological diagnosis is difficult, and a significant number of cases do not respond to treatment. Generally, $2-5 \%$ of TL cases in which the primary infection heals subsequently develop ML (Marsden, 1990). Leishmania persistence following clinical treatment may be responsible for recurrence of the disease (Schubach et al., 1998). LCL and ML represent responsive facets of the disease, with immune responses that are readily detected.

Diffuse cutaneous leishmaniasis, caused by L. amazonensis, is a rare but severe manifestation of the disease that develops in anergic patients and is characterized by a defective cellular immune response to Leishmania antigens (Convit et al., 1962). In this case, a single ulcer slowly evolves, developing plaques or multiple non-ulcerated nodules. Diffuse cutaneous leishmaniasis responds poorly to treatment, and Leishmania skin tests are negative.

In this review, we will focus on recent advances in understanding the complexity of TL caused by L. braziliensis, focusing on both experimental models of infection and pathogenesis in the human host. We will also discuss certain aspects of infection with $L$. amazonensis, given its sole association with diffuse cutaneous leishmaniasis and the singular characteristics of this disease. We aim to provide a current picture of the complex hostparasite interactions involved in leishmaniasis while also taking into account the role of the vector's saliva, an area of intense research in the past several years.

It is important to understand recent findings regarding intrinsic differences within the Leishmania species when addressing L. braziliensis pathogenesis. These differences came to light following vaccination attempts using the $L$. braziliensis homologs of the receptor for activated $\mathrm{C}$ kinase (LACK), thiol-specific antioxidant (TSA), Leishmania elongation and initiation factor (LeIF1), and L. major stress-inducible protein 1 (LmSTI1; Salay et al., 2007). All four open reading frames have a high degree of homology at the 
amino acid level with previously described $L$. major genes. However, immunization failed to significantly reduce lesions following challenge with $L$. braziliensis.

A comparison between the genomes of $L$. (L.) major, $L$. $(L$.) infantum chagasi, and L. braziliensis showed elevated gene synteny, expected for species belonging to the same genus, with only 200 genes differentially distributed between the three species. Moreover, few genes are species-specific, and only 47 genes are specific to $L$. braziliensis. However, the greatest surprise was that genes related to RNAi machinery have only been found in L. braziliensis (Peacock et al., 2007). Mobile elements such as retrotransposons were also identified in L. braziliensis but are absent in L. major and L. infantum, both of which are RNAideficient (Peacock et al., 2007) Importantly, the RNAi machinery in L. braziliensis is functional (Lye et al., 2010) enabling the downregulation of reporter and endogenous genes. The RNAi pathway in L. braziliensis could potentially help protect against mutations caused by mobile elements (Shi et al., 2004). Double-strand (ds) RNA viruses (LRVs) can infect L. braziliensis (Tarr et al., 1988; Patterson, 1993), and the RNAi response may help to protect against such infection (Anderson et al., 2007). However, infection with LRV increased parasite survival and pathogenesis in L. guyanensis (Ives et al., 2011), raising the possibility that, in RNAi-competent Leishmania, LRV infection may actually down-modulate RNAi activity.

\section{INNATE IMMUNITY IN LEISHMANIASIS TRIGGERED \\ BY L. BRAZILIENSIS}

$\mathrm{BALB} / \mathrm{c}$ mice infected in the ear dermis with $L$. braziliensis develop cutaneous lesions at the site of inoculation (de Moura et al., 2005), and histological analysis of ear sections demonstrated constant recruitment of neutrophils to the inoculation site. Interestingly, neutrophil depletion during L. braziliensis infection increased parasite load, whereas BALB/c mice co-inoculated with both parasites and live neutrophils displayed lower parasite loads at the site of infection and in the draining lymph nodes (Novais et al., 2009). In vitro, co-cultures of live neutrophils and L. braziliensis-infected macrophages led to a decrease in parasite load, and elimination of $L$. braziliensis elimination was associated with TNF- $\alpha$ and superoxide production (Novais et al., 2009). In experiments using L. amazonensis, phagocytosis of apoptotic human neutrophils by L. amazonensis-infected macrophages led to an increase in parasite burden in a TGF- $\beta$ and $\mathrm{PGE}_{2}$-dependent manner. Conversely, uptake of necrotic neutrophils by infected macrophages led to killing of L. amazonensis. Leishmanicidal activity was dependent on TNF- $\alpha$ and neutrophil elastase and was also associated with superoxide production (Afonso et al., 2008). Another function attributed to the neutrophils is the production of neutrophil extracellular traps (NETs) which are composed of filamentous genomic DNA containing antimicrobial peptides. L. amazonensis parasites are susceptible to killing by humans NETs, and LPG isolated from these parasites triggered NET release (Guimaraes-Costa et al., 2009).

L. braziliensis induced the production of CXCL-10 and IL-10 by human peripheral blood mononuclear cells (PBMCs) and macrophages, but the enhanced expression of CXCL10 and its receptor, CXCR3, was predominantly detected in $\mathrm{CD} 14^{+}$ monocytes. Interestingly, sera from TL patients, and especially those from ML patients, have significantly higher levels of CXCL10, CCL4, and soluble TNF receptor II (sTNFRII) than sera from control individuals. These multiple inflammatory mediators produced by the host may contribute to disease severity by increasing cellular recruitment (Vargas-Inchaustegui et al., 2010). However, IL-10 production is important in controlling the exacerbated inflammatory response characteristic of TL. Antonelli et al. (2004) showed a strong positive correlation between IL-10 and TNF- $\alpha$-producing monocytes in PBMC cultures from LCL patients stimulated with soluble Leishmania antigen (SLA), suggesting that an intrinsic macrophage auto-regulation mechanism appears to be active in LCL patients.

Interferon- $\beta$ increases the parasite load in infected human macrophages following infection with New World parasites (L. braziliensis and L. amazonensis) in a manner that is independent of endogenous and exogenous NO (Khouri et al., 2009). In parallel, IFN- $\beta$ significantly reduces superoxide release by both Leishmania-infected and uninfected human macrophages. This reduction was accompanied by a significant increase in superoxide dismutase (SOD1) protein levels. Biopsies from New World cutaneous leishmaniasis patients show pronounced SOD-1 expression levels in situ (Khouri et al., 2009). Importantly, these results suggest that IFN- $\beta$ production in human Leishmaniasis may be deleterious, particularly in DCL cases where the parasite load is elevated. Similarly, TGF- $\beta$ also plays a major role in macrophage deactivation, leading to increased parasite load in an experimental model of L. amazonensis infection (Barral et al., 1992). Subsequently, parasite killing following $L$. amazonensis infection has been observed in vitro in experiments using the superoxide-dismutase inhibitor diethyldithiocarbamate (DETC; Khouri et al., 2010). Moreover, in vivo treatment with DETC significantly decreased lesion size and parasite load in an experimental model of $L$. braziliensis infection.

Systemic administration of Leishmania parasites, including L. braziliensis, induces in vivo DC maturation characterized by DC migration to $\mathrm{T}$ cell areas and costimulatory molecule upregulation (Antonelli et al., 2004). DCs co-cultured with L. braziliensis up-regulate DC activation markers and produce IL- 12 and TNF- $\alpha$. However, up-regulation of activation markers and IL-12 production was primarily confined to bystander (uninfected) DCs (Carvalho et al., 2008). The authors of this study proposed that bystander DCs in L. braziliensis infection lead to T cell activation, while infected DCs contribute to parasite control through enhanced TNF- $\alpha$ production. Indeed, experimentally infected TNF- $\alpha^{-/-}$mice developed non-healing skin lesions (Rocha et al., 2007). Likewise, axenic L. braziliensis amastigotes successfully stimulated DCs to produce IL-12p40, inducing an activated phenotype (Vargas-Inchaustegui et al., 2008). DCs infected with L. braziliensis show increased phosphorylation of STAT molecules and ISG15 expression (IFN-stimulated gene 15). Accordingly, in vivo infection with $L$. braziliensis led to a self-healing phenotype characterized by increased numbers of IFN- $\gamma$ - and IL-17-secreting $\mathrm{CD}^{+} \mathrm{T}$ cells. DCs from MyD88 ${ }^{-/-}$mice exhibited less activation and decreased production of IL-12 during experimental L. braziliensis infection, suggesting a role for TLR involvement (Vargas-Inchaustegui et al., 2009). Furthermore, MyD88 ${ }^{-/-}$mice developed larger lesions than control mice. However, a lack of 
TLR2 resulted in enhanced DC activation, increased IL-12 production and successful priming of naïve $\mathrm{CD} 4^{+} \mathrm{T}$ cells. Fully understanding the role of TLRs in L. braziliensis infection will require further research.

\section{ADAPTIVE IMMUNITY IN HUMAN LEISHMANIASIS}

In general, patients with LCL and ML have a strong type 1 immune response to Leishmania antigen, with high production of IFN- $\gamma$ and TNF- $\alpha$ and decreased efficacy of IL-10 in down-modulating IFN- $\gamma$ production (Follador et al., 2002). With disease progression, ML patients tend to develop stronger intradermal skin test reactions, and their lymphocytes exhibit stronger proliferative responses and IFN- $\gamma$ production than cells from LCL patients. However, antigen-stimulated PBMCs from $50 \%$ of subjects who developed the disease within the previous 60 days exhibit low or absent IFN- $\gamma$ levels. This response can be restored by either IL-12 or anti-IL-10 monoclonal antibodies (Ribeiro-de-Jesus et al., 1998). Later in the disease course, both LCL and MCL patients exhibited high levels of IFN- $\gamma$ and TNF- $\alpha$, but TNF- $\alpha$ levels decreased following treatment. IFN- $\gamma$ and TNF- $\alpha$ seem to be involved in both controlling parasite multiplication during the early phases of Leishmania infection and mediating the tissue damage observed in TL (Ribeiro-de-Jesus et al., 1998). In a recent study, Oliveira et al. (2011) observed a positive correlation between ulcer size at the time of the first evaluation, time to recovery, and TNF- $\alpha$ levels, supporting the use of TNF- $\alpha$ inhibitors combined with standard therapy to improve recovery time in LCL patients with severe lesions. In fact, pentoxifylline has been successfully used to decrease recovery time in ML patients, even in those that were refractory to conventional treatment (Lessa et al., 2001; Bafica et al., 2003).

Infection with $L$. braziliensis has been associated with lymphadenopathy in the absence of tegumentary lesions (skin or mucosal; Barral et al., 1992, 1995a). Lymphadenopathy can precede the appearance of skin ulcers and must be differentiated from the satellite lymph node enlargement associated with lesion establishment. Cells obtained from lymph nodes from LCL patients without ulcerations (early phase) exhibited a higher proportion of neutrophils, eosinophils, and $\mathrm{CD}^{+} \mathrm{T}$ cells. In contrast, $\mathrm{CD} 19^{+} \mathrm{B}$ cells and plasma cells were more frequently observed in patients showing lymphadenopathy with ulcerations (late phase; Bomfim et al., 2007). IL-10 transcription was significantly higher in late-phase disease, suggesting an important role for this cytokine in limiting tissue damage. IFN- $\gamma$ and IL-4 levels were similar in both groups of patients, reinforcing the concept of a mixed Th1-Th2 profile during disease. These results highlight the role of $\mathrm{CD}^{+} \mathrm{T}$ cells in the early phase of $\mathrm{CL}$, as shown by Pompeu et al. (2001) using a model of in vitro priming. Additionally, there is a temporal relationship between ulcer development and the increased numbers of B cells. Cells from patients exhibiting ulcers typical of LCL-produced IFN- $\gamma$ and TNF- $\alpha$ upon stimulation with SLA or LACK, which originated from multiple sources, including $\mathrm{CD}^{+}{ }^{+}$and $\mathrm{CD}^{+}{ }^{+} \mathrm{T}$ cells (Bottrel et al., 2001). A positive correlation was observed between IFN- $\gamma$ or TNF- $\alpha$ and IL-10 production from lymphocytes. Higher frequencies of IL-10producing parasite-specific lymphocytes are correlated with lower frequencies of TNF- $\alpha$-producing monocytes, demonstrating the role of antigen-specific IL-10 production in negatively regulating monocyte activity (Antonelli et al., 2004, 2005).

Studies of different V $\beta$ T cells in LCL patients have revealed an association between TCR V $\beta 12$ expressions, T cell activation and IFN- $\gamma$ production after in vitro priming with Leishmania (Clarencio et al., 2006). More recently, Keesen et al. (2011) measured the expansion, activation state, and functional potential of specific $\mathrm{T}$ cells identified by their TCR V $\beta$ expression. They observed an increase in CD4 V $\beta$ 5.2- and V $\beta$ 24-positive T cells in LCL patients compared to controls, a profile suggesting previous activation of the CD4 Va 5.2-, 11-, and 24-positive T cells characterized by increased expression of CD45RO, HLA-DR, IFN- $\gamma$, TNF- $\alpha$, and IL-10 compared to the other V $\beta$-expressing subpopulations and a positive correlation between higher frequencies of CD4 V $\beta 5.2 \mathrm{~T}$ cells and lesion size. The identification of active subpopulations in this form of the disease could allow for the identification of the immunodominant Leishmania antigens responsible for triggering an efficient host response against the parasite and could also allow for identification of the cell populations involved in disease pathology.

In L. braziliensis endemic areas, approximately $10 \%$ of the individuals have a positive delayed-type hypersensitivity (DTH) skin test to Leishmania antigen but have neither a previous history of LCL nor a typical LCL scar. These individuals are categorized as having a subclinical (SC) L. braziliensis infection (Follador et al., 2002). Individuals with SC $L$. braziliensis infection produce significantly lower levels of IFN- $\gamma$ and TNF- $\alpha$ than patients with active LCL. However, IL-10 levels are higher in these individuals than in LCL patients (Bittar et al., 2007). Recently, Novoa et al. (2011) reported stronger Th1 responses in LCL patients than in SC individuals. This finding seems be unaffected by IL-10, as levels of this cytokine at both the protein and mRNA levels were very similar in both groups. IL-27 is a cytokine that both initiates a Th1 response and regulates inflammation (Trinchieri et al., 2003; Yoshimura et al., 2006). IL-27 mRNA levels were higher in cells from LCL patients than in those from SC patients following stimulation with $L$. braziliensis. The mechanisms by which SC individuals control parasite growth are unknown. Because the adaptive immune responses in these individuals is less prominent, we can speculate that parasite control may be dependent on innate immune responses, with the participation of neutrophils (Novais et al., 2009), macrophages, and NK cells of particular importance. Interestingly, PBMC IL-17 production is slightly higher in SC patients than in LCL patients, suggesting a possible protective role for this cytokine. However, IL-17 could be exerting different functions based on the phase of disease. Our group recently illustrated the involvement of IL-17 and IL-17-inducing cytokines in biopsy specimens from ML patients. IL-17 was expressed by $\mathrm{CD}^{+}, \mathrm{CD}^{+}$, and $\mathrm{CD}^{+} 4^{+}$cells, and numerous $\mathrm{IL}-17^{+}$cells co-expressed CCR6. We also observed the presence of neutrophils in necrotic and perinecrotic areas; these neutrophils stained positive for neutrophil elastase, myeloperoxidase, and MMP-9, indicating that IL-17 could be involved in ML pathogenesis (Boaventura etal., 2010). In fact, in vitro infection of human macrophages with L. braziliensis increased the secretion and activation of MMP-9, and macrophages from cured individuals with previous histories of ML exhibited 
increased MMP-9 activity than those from cured LCL patients (Maretti-Mira et al., 2011).

Mucosal leishmaniasis patients display an exacerbated and unregulated immune response. They have a higher frequency of activated $\mathrm{T}$ cells than patients with LCL, as measured by different activation markers. While LCL patients displayed a positive correlation between IL-10 and TNF- $\alpha$-producing monocytes, ML patients did not. This lack of correlation between IL-10-producing and TNF- $\alpha$ producing monocytes in ML patients could lead to a poorly controlled inflammatory response in vivo, and cytokine networks may be involved in the development of immunopathology in ML patients (Gaze etal., 2006). Additionally, IL-10 receptor expression was lower in ML lesions than in LCL lesions (Faria et al., 2005).

\section{ROLE OF CD8 ${ }^{+} \mathrm{T}$ CELLS}

The role of cytotoxicity in host defense and tissue damage during human LCL is not yet well understood. Machado et al. (2002) observed the presence of NK cells, $\mathrm{CD}^{+}$and CD45RO+ T cells, and strong expression of TIA-1, a molecule associated with cytotoxicity, in the dermal cell infiltrates of lesions from LCL patients. The presence of these cytolytic cells in LCL lesions suggests active participation of $\mathrm{NK}$ and $\mathrm{CD} 8^{+} \mathrm{T}$ cells in the pathogenesis of this disease. These cells may play a role in both parasite killing and ulcer development (Machado et al., 2002). More recently, Faria et al. (2009) characterized the immunological kinetics associated with LCL progression, comparing the cellular composition and cytokine and granzyme expression in lesions of patients with early-stage (E-LCL) and late-stage LCL (L-LCL). Histopathological analysis showed that lesions from L-LCL patients displayed more exuberant inflammatory infiltration than those from E-LCL patients. Although E-LCL and L-LCL lesions were predominantly mononuclear, lesions from E-LCL patients presented higher neutrophil and eosinophil counts than those from L-LCL patients. $\mathrm{CD}^{+} \mathrm{T}$ cells from L-LCL lesions expressed significantly higher levels of granzyme A than those from E-LCL lesions. Interestingly, granzyme A expression was positively correlated with the intensity of the inflammatory infiltrate in L-LCL patients but not in E-LCL patients. These results suggest that the recruitment of $\mathrm{CD}^{+}$and granzyme $\mathrm{A}^{+} \mathrm{T}$ cells is involved in lesion progression in human LCL. Our group found similar results, showing that lesions from CL patients presented higher frequencies of $\mathrm{CD}^{+}$ T cells displaying CLA (cutaneous lymphocytes antigen); these cells are mainly cytolytic, with strong expression of CD107 and granzyme B. They also produce IFN- $\gamma$ and IL-10, but in lower frequencies than $\mathrm{CD} 4{ }^{+} \mathrm{T}$ cells (Silva et al., submitted manuscript). Mendes-Aguiar Cde et al. (2009) also observed that the CLA receptor could direct Leishmania-specific $\mathrm{CD} 8^{+} \mathrm{T}$ lymphocytes toward inflamed skin lesions, suggesting that Leishmania antigens could modulate the molecules responsible for skin lesions, affecting the cell composition of the inflammatory infiltrate in Leishmaniasis. $\mathrm{CD}^{+} \mathrm{T}$ cells seem to play distinct roles in different phases of the disease. Using an in vitro priming assay (IVP), we observed that $\mathrm{CD}^{+} \mathrm{T}$ cells are the first cells to be activated by Leishmania promastigotes and to produce IFN- $\gamma$, which is partially responsible for directing the differentiation of Th1 cells (Pompeu et al., 2001). However, CD8 ${ }^{+}$T cells and NK cells also contribute to the tissue destruction observed in ML patients in late stages of disease (Brodskyn et al., 1997).

\section{IMMUNOSUPPRESSION IN LEISHMANIASIS}

In spite of a robust immune response, a small number of parasites persist following the resolution of leishmaniasis (Mendonca et al., 2004; Figueroa et al., 2009; Martins et al., 2010). In mice infected with $L$. braziliensis in the ear dermis, parasites also persist in draining lymph nodes, despite lesion resolution and parasite clearance from the infection site (de Moura et al., 2005). In mice, IL-10 blockade following infection with low doses leads to a sterile cure of the disease (Belkaid et al., 2001). In Leishmaniasis, this cytokine can be produced by several different cell sources, including Treg cells (Belkaid et al., 2002), Th1 cells (Stager et al., 2006; Anderson et al., 2007; Nylen et al., 2007); CD8 ${ }^{+}$T cells (Belkaid et al., 2002), B cells (Ronet et al., 2010), NK cells (Maroof et al., 2008), regulatory DCs (Svensson et al., 2004), macrophages (Miles et al., 2005), and neutrophils (McFarlane et al., 2008). In patients, functional Treg cells could be found in the skin lesions of patients with LCL. These cells expressed phenotypic markers of Treg cells, including CD25, CTLA-4, Foxp3, and GITR (glucocorticoid-induced tumor necrosis factor receptor), and were able to produce large amounts of IL- 10 and TGF- $\beta$. CD $4^{+} \mathrm{CD} 25^{+} \mathrm{T}$ cells derived from the lesions of patients with LCL suppressed the PHA-induced proliferative $\mathrm{T}$ cell responses of allogeneic PBMCs from healthy controls (Campanelli et al., 2006). These findings suggest that functional Treg cells accumulate at sites of Leishmania infection in humans and possibly contribute to the local control of effector T cell functions.

Another important immunosuppressive cytokine involved is TGF- $\beta$. This cytokine has different effects on cells in the immune system, including down-regulation of certain macrophage functions. As commented earlier, this cytokine is produced by macrophages present in the lesions of mice infected with L. amazonensis (Barral-Netto et al., 1992). Human macrophages produce active TGF- $\beta$ after infection with $L$. amazonensis, L. chagasi, and L. braziliensis. The addition of this cytokine to cultures of L. braziliensis-infected macrophages led to an increase in parasite numbers compared to untreated cultures. Fibroblasts in the dermis could be immunostained for TGF- $\beta$, as could inflammatory cells from the biopsies of human lesions on occasion - mainly from patients with early cutaneous leishmaniasis (less than 2 months following ulcer development) and in cases of active mucosal leishmaniasis (Barral etal., 1995b). These results suggest that this cytokine could be important for the establishment of infection and as a feedback mechanism following the development of an acute inflammatory response.

\section{EXPERIMENTAL INFECTION WITH L. BRAZILIENSIS: INSIGHTS INTO HUMAN PATHOGENESIS?}

Initial studies conducted with inbred mice infected with $L$. braziliensis revealed a broad range of responses. AKR/J and CBA/J mice showed only a mild and transient swelling of the nose. SWR/J, $\mathrm{C} 57 \mathrm{~L} / \mathrm{J}, \mathrm{A} / \mathrm{J}, \mathrm{A} / \mathrm{HeJ}$, and DBA/1J mice showed initial nodules, which eventually healed. In contrast, BALB/cJ mice were considered susceptible based on progressive dermal lesions (Childs et al., 1984). However, analysis of the immune response has 
shown that L. braziliensis-infected BALB/c mice produce less IL-4 than $L$. major-infected mice, and treating L. braziliensis-infected $\mathrm{BALB} / \mathrm{c}$ mice with anti-IFN- $\gamma$ significantly enhanced lesion size and prevented mice from resolving the infection (DeKrey et al., 1998). These authors suggest that an IFN- $\gamma$-dependent mechanism is responsible for killing L. braziliensis in BALB/c mice and that the weak infectivity of $L$. braziliensis in this mouse strain may be due to the inability of the parasite to elicit a strong and sustained IL-4 production. In a recent study, mice inoculated with an antimony-resistant L. braziliensis strain displayed an increased IL-4 response and elevated Arginase I expression (Costa et al., 2011). Treatment with an anti-IL-4 monoclonal antibody resulted in decreased lesion thickness and parasite load. Therefore, the capacity of L. braziliensis isolates to induce a Th2-type response, characterized by presence of IL-4, contributes to the virulence and severity of disease.

Using the footpad model of infection, we showed that mice infected with a L. braziliensis strain from Ceará (H3227) developed detectable lesions, whereas mice infected with a different strain (BA788), isolated in Bahia, did not (Indiani de Oliveira et al., 2004). Early after parasite inoculation, lymph node cells from BA788-parasitized mice produced higher levels of IFN- $\gamma$ and had higher numbers of NK cells than H3227-infected mice. Importantly, the L. braziliensis strain from Ceará (H3227) is genotypically different from the L. braziliensis strain from Bahia (BA788). Therefore, variation in the pathogenicity of these different L. braziliensis strains correlated with their genetic diversity. Interestingly, in Ceará state, where the H3227 L. braziliensis isolate was obtained, prominent lymphadenopathy can precede skin lesion appearance (Sousa Ade et al., 1995), suggesting that important correlates can be drawn from the mouse model. In a subsequent study using the same two strains, the H3227 L. braziliensis strain induced significantly stronger cellular recruitment than the BA788 strain, which correlated with higher expression of CCL2, CCL3, and CXCL1 (Teixeira et al., 2005). In contrast, L. braziliensis BA788 significantly up-regulated CXCL10 expression, which correlated with earlier IFN- $\gamma$ production and with a higher number of NK cells present at the infection site (Indiani de Oliveira et al., 2004).

$\mathrm{BALB} / \mathrm{c}$ mice infected with a Leishmania strain isolated from a ML patient developed a rapidly progressing and widely metastatic disease resembling diffuse cutaneous leishmaniasis (Barral et al., 1983). Although C57BL/6 mice initially contained parasite multiplication and appeared clinically cured, subsequent disease developed that was characterized by distinctive ulcerative metastases and destruction of the nasal region, similar to what is observed in ML. Disease development in these mouse strains was associated with a decrease in cell-mediated immunity, as monitored by delayed type hypersensitivity and lymphoproliferative responses. Footpad injection of metacyclic L. braziliensis into $\mathrm{C} 57 \mathrm{BL} / 6$ mice confirmed the initial findings regarding disease outcome in this mouse strain, as the mice control infection and parasite multiplication in the draining lymph nodes (Maioli et al., 2004). This phenotype was associated with increased levels of IFN- $\gamma$ and TNF- $\alpha$ and a superior lymphoproliferative response. Importantly, in the same study, the authors demonstrated that L. amazonensis infection leads to chronic lesion development with elevated parasite numbers and a decreased cellular response, highlighting the differences in immune regulation induced by the distinct New World Leishmania species.

As has been thoroughly described in the literature, mice from BALB strains are highly susceptible to L. major infection, and this susceptibility is linked to a predominant Th2 response characterized by the presence of IL-4 (reviewed in Belkaid et al., 2002). In a comparative study, BALB/c mice infected subcutaneously with $L$. braziliensis developed small, nodular lesions that selfhealed, in contrast to L. major-infected BALB/c mice, which displayed progressive ulcers (Rocha etal., 2007). This phenotype was confirmed by intradermal infection with L. braziliensis, after which mice develop ulcerated lesions (similar to the lesions that develop upon natural infection) that heal spontaneously (de Moura et al., 2005). In this model, a mixed Th1/Th2 immune response was observed that was characterized by the presence of IFN- $\gamma$, IL-4, and IL-10-secreting cells, which is distinct from the Th2-polarized response observed following L. major infection. Interestingly, parasites are cleared from the infection site following lesion healing but persist within draining lymph nodes, suggesting that immunoregulatory mechanisms allow for parasite survival. Indeed, the presence of $\mathrm{CD} 4{ }^{+} \mathrm{CD} 25^{+} \mathrm{T}$ cells expressing regulatory markers such as Foxp3, GITR, and CD103 has been described following L. braziliensis infection (Costa et al., 2011; Falcão et al., 2012).

A similar phenotype was also observed in C57BL/6 mice. The "resistance" observed in L. braziliensis-infected mice of this strain was associated with significantly lower IL-4 and IL-13 production in parallel with increased presence of IFN- $\gamma$ and iNOS. Previous work has shown that IFN- $\gamma^{-/}$mice infected with L. braziliensis develop uncontrolled lesions (DeKrey et al., 1998), while IL-12p40-/ - mice, which lack both IL-12 and IL-23, develop chronic lesions (de Souza-Neto et al., 2004). As lymphocytes from the latter produce decreased levels of IFN- $\gamma$, this further implicates IFN- $\gamma$ in the control of L. braziliensis infection. These results were confirmed by infecting IL-12p35-/mice, which lack IL-12 only. These mice display uncontrolled lesions, as do IL-12p35p40-/- mice (Rocha et al., 2007). A similar phenotype was observed following infection of STAT4 ${ }^{-/-}$mice, implicating IL-12 in the immune response to L. braziliensis. Lastly, $\mathrm{iNOs}^{-/-}$mice develop progressive non-healing lesions and have an increased parasite load within the draining lymph nodes (Rocha et al., 2007). The lesions self heal in mice lacking gp91phox, indicating that only iNOS is essential for controlling L. braziliensis infection.

\section{NEW WORLD LEISHMANIASIS AND THE ROLE OF SAND FLY SALIVA}

Several attempts have been made to reproduce the biology of natural transmission, taking into account parasite load (sand flies inoculate low numbers of parasites), the presence of saliva (parasites are injected into the host's skin in conjunction with sand fly saliva) and the site of inoculation (parasites are injected by the sand fly into the dermal compartments of the skin). $\mathrm{BALB} / \mathrm{c}$ mice inoculated in the ear dermis with L. braziliensis develop ulcerated lesions (de Moura et al., 2005), but coinoculation of parasites plus sand fly saliva exacerbates infection 
(Samuelson et al., 1991), which is associated with elevated IL-4 production (Lima and Titus, 1996). Similarly, co-inoculation with L. amazonensis and sand fly saliva also exacerbates infection; however, in this context, it was associated with increased IL-10 levels (Norsworthy et al., 2004). Moreover, mice injected with parasites in the presence of saliva developed lesions with heavily parasitized epithelioid macrophages, persistent neutrophils and eosinophils, and minimal fibroplasia, indicating that sand fly saliva modifies the inflammatory response during infection with $L$. braziliensis. Of note, this disease exacerbation in the presence of saliva was dependent on the sand fly species, as co-inoculation with L. braziliensis and Lu. whitmani saliva led to the development of lesions that heal spontaneously (Bezerra and Teixeira, 2001).

Pre-exposure to saliva or to bites from uninfected sand flies has been shown to result in protection against subsequent infection with New World species such as L. amazonensis (Thiakaki et al., 2005) and L. chagasi (Gomes et al., 2008). In contrast, preexposure to $L u$. intermedia saliva enhanced $L$. braziliensis infection in the mouse model; additionally, disease exacerbation was correlated with the generation of a Th2 response, as evidenced by a reduction in the IFN- $\gamma / \mathrm{IL}-4$ ratio (de Moura et al., 2007). Importantly, individuals with active LCL showed stronger humoral immune responses to $\mathrm{Lu}$. intermedia saliva than control subjects, a finding also true for Old World LCL (Rohousova et al., 2005). These data indicate an association between disease and the immune response to $\mathrm{Lu}$. intermedia saliva in humans. As mentioned earlier, sand fly saliva modifies the inflammatory response to infection with L. braziliensis (Lima and Titus, 1996). Indeed, pre-treatment of human monocytes with $L u$. intermedia saliva followed by $L$. braziliensis infection led to a significant increase in TNF- $\alpha$, IL-6, and IL-8 production (Menezes et al., 2008), indicating the capacity of $L u$. intermedia saliva to alter the inflammatory milieu. Stimulation with $\mathrm{Lu}$. intermedia salivary proteins markedly increased leukocyte recruitment, and mice immunized with $L u$. intermedia saliva showed a concomitant increase in CXCL1, CCL2, CCL4, and TNF- $\alpha$ expression (de Moura et al., 2010). Upon stimulation with $L$. braziliensis, however, IL-10 up-regulation was observed, confirming that pre-exposure to $\mathrm{Lu}$. intermedia is able

\section{REFERENCES}

Afonso, L., Borges, V. M., Cruz, H., Ribeiro-Gomes, F. L., DosReis, G. A., Dutra, A. N., Clarencio, J., de Oliveira, C. I., Barral, A., BarralNetto, M., and Brodskyn, C. I. (2008). Interactions with apoptotic but not with necrotic neutrophils increase parasite burden in human macrophages infected with Leishmania amazonensis. J. Leukoc. Biol. 84, 389-396.

Anderson, C. F., Oukka, M., Kuchroo, V. J., and Sacks, D. (2007). CD4(+)CD25(-)Foxp3(-) Th1 cells are the source of IL-10-mediated immune suppression in chronic cutaneous leishmaniasis. J. Exp. Med. 204, 285-297.

Antonelli, L. R., Dutra, W. O., Almeida, R. P., Bacellar, O., and Gollob, K.

to modify the inflammatory environment and, in doing so, favors L. braziliensis establishment.

Several groups have examined the possibility of vaccination using salivary antigens. Immunization with a DNA plasmid coding for the SP15 Phlebotomus papatasi protein was effective in providing protection against infection by L. major (Valenzuela et al., 2001). In parallel, we have shown that hamsters immunized with a DNA plasmid coding for LJM19, a protein present in Lu. longipalpis saliva, were protected against the development of visceral leishmaniasis (Gomes et al., 2008). LJM19-immunized hamsters maintained a low parasite load that correlated with high IFN- $\gamma /$ TGF- $\beta$ ratio and iNOS production. Importantly, a delayed-type hypersensitivity (DTH) response with high expression of IFN- $\gamma$ was also detectible in the skin of LJM19-immunized animals. These studies suggested that a DTH response generated against salivary antigens such as SP15 or LJM19 might be the mechanism underlying protective anti-Leishmania immunity. Based on this hypothesis, we have shown that immunization with a DNA plasmid coding for LJM19, a protein present in Lu. longipalpis saliva, conferred protection against L. braziliensis (Tavares et al., 2011). These results suggest the possibility of using salivary antigens to generate protection against different species of Leishmania.

\section{CONCLUDING REMARKS}

Although Leishmania infection has been widely used to elucidate many aspects of the immune response to intracellular pathogens, we still do not fully understand the immunopathogenesis of the human disease. It is clear that LCL and ML caused by L. braziliensis are diseases in which immunoregulation, rather than parasite multiplication per se, plays a major role. Moreover, DCL caused by $L$. amazonensis is a disease that completely lacks a cellular immune response. Collectively, these major differences urge for more studies focused on human immunology. The experimental mouse intradermal infection model using L. braziliensis recapitulates many aspects of the human infection; as such, it will prove a useful tool for dissecting aspects of both the innate and the adaptive immune response to this important representative of New World leishmaniasis.

Barral, A., Barral-Netto, M., Almeida, R., de Jesus, A. R., Grimaldi, G. Jr., Netto, E. M., Santos, I., Bacellar, O., and Carvalho, E. M. (1992). Lymphadenopathy associated with Leishmania braziliensis cutaneous infection. Am. J. Trop. Med. Hyg. 47, 587-592.

Barral, A., Guerreiro, J., Bomfim, G., Correia, D., Barral-Netto, M., and Carvalho, E. M. (1995a). Lymphadenopathy as the first sign of human cutaneous infection by Leishmania braziliensis. Am. J. Trop. Med. Hyg. 53, 256-259.

Barral, A., Petersen, E. A., Sacks, D. L., and Neva, F. A. (1983). Late metastatic Leishmaniasis in the mouse. A model for mucocutaneous disease. Am. J. Trop. Med. Hyg. 32, 277-285.
Barral, A., Teixeira, M., Reis, P., Vinhas, V., Costa, J., Lessa, H., Bittencourt, A. L., Reed, S., Carvalho, E. M., and Barral-Netto, M. (1995b). Transforming growth factor-beta in human cutaneous leishmaniasis. Am. J. Pathol. 147, 947-954.

Barral-Netto, M., Barral, A., Brownell, C.E., Skeiky, Y. A., Ellingsworth, L. R., Twardzik, D. R., and Reed, S. G. (1992). Transforming growth factorbeta in leishmanial infection: a parasite escape mechanism. Science 257, 545-548.

Belkaid, Y., Hoffmann, K. F., Mendez, S., Kamhawi, S., Udey, M. C., Wynn, T. A., and Sacks, D. L. (2001). The role of interleukin (IL)10 in the persistence of Leishmania major in the skin after healing and the therapeutic potential of 
anti-IL-10 receptor antibody for sterile cure. J. Exp. Med. 194, 14971506.

Belkaid, Y., Piccirillo, C. A., Mendez, S., Shevach, E. M., and Sacks, D. L. (2002). CD4+CD25+ regulatory $\mathrm{T}$ cells control Leishmania major persistence and immunity. Nature 420, 502-507.

Bezerra, H. S., and Teixeira, M. J. (2001). Effect of Lutzomyia whitmani (Diptera: Psychodidae) salivary gland lysates on Leishmania (Viannia) braziliensis infection in BALB/c mice. Mem. Inst. Oswaldo Cruz. 96, 349-351.

Bittar, R. C., Nogueira, R. S., VieiraGoncalves, R., Pinho-Ribeiro, V., Mattos, M. S., Oliveira-Neto, M. P., Coutinho, S. G., and Da-Cruz, A. M. (2007). T-cell responses associated with resistance to Leishmania infection in individuals from endemic areas for Leishmania (Viannia) braziliensis. Mem. Inst. Oswaldo Cruz. 102, 625-630.

Boaventura, V. S., Santos, C. S., Cardoso, C. R., de Andrade, J., Dos Santos, W. L., Clarencio, J., Silva, J. S., Borges, V. M., Barral-Netto, M., Brodskyn, C. I., and Barral, A. (2010). Human mucosal leishmaniasis: neutrophils infiltrate areas of tissue damage that express high levels of Th17-related cytokines. Eur. J. Immunol. 40, 2830-2836.

Bomfim, G., Andrade, B. B., Santos, S., Clarencio, J., Barral-Netto, M., and Barral, A. (2007). Cellular analysis of cutaneous leishmaniasis lymphadenopathy: insights into the early phases of human disease. Am. J. Trop. Med. Hyg. 77, 854-859.

Bottrel, R. L., Dutra, W. O., Martins, F. A., Gontijo, B., Carvalho, E., Barral-Netto, M., Barral, A., Almeida, R. P., Mayrink, W., Locksley, R., and Gollob, K. J. (2001). Flow cytometric determination of cellular sources and frequencies of key cytokine-producing lymphocytes directed against recombinant LACK and soluble Leishmania antigen in human cutaneous leishmaniasis. Infect. Immun. 69, 3232-3239.

Brodskyn, C. I, Barral, A., Boaventura, V., Carvalho, E., and BarralNetto, M. (1997). Parasite-driven in vitro human lymphocyte cytotoxicity against autologous infected macrophages from mucosal leishmaniasis. J. Immunol. 159, 4467-4473.

Campanelli, A. P., Roselino, A. M., Cavassani, K. A., Pereira, M. S., Mortara, R. A., Brodskyn, C. I., Goncalves, H. S., Belkaid, Y., Barral-Netto, M., Barral, A., and Silva, J. S. (2006). $\mathrm{CD} 4^{+} \mathrm{CD} 25^{+} \mathrm{T}$ cells in skin lesions of patients with cutaneous leishmaniasis exhibit phenotypic and functional characteristics of natural regulatory $\mathrm{T}$ cells. J. Infect. Dis. 193, 13131322.

Carvalho, L. P., Pearce, E. J., and Scott, P. (2008). Functional dichotomy of dendritic cells following interaction with Leishmania braziliensis: infected cells produce high levels of TNFalpha, whereas bystander dendritic cells are activated to promote $\mathrm{T}$ cell responses. J. Immunol. 181, 64736480.

Childs, G. E., Lightner, L. K., McKinney, L., Groves, M. G., Price, E. E., and Hendricks, L. D. (1984). Inbred mice as model hosts for cutaneous leishmaniasis. I. Resistance and susceptibility to infection with Leishmania braziliensis, L. mexicana, and $L$. aethiopica. Ann. Trop. Med. Parasitol. 78, 25-34.

Clarencio, J., de Oliveira, C. I., Bomfim, G., Pompeu, M. M., Teixeira, M. J., Barbosa, T. C., Souza-Neto, S., Carvalho, E. M., Brodskyn, C., Barral, A., and Barral-Netto, M. (2006). Characterization of the T-cell receptor Vbeta repertoire in the human immune response against Leishmania parasites. Infect. Immun. 74, 47574765.

Convit, J., Kerdel-Vargas, F., and Gordon, B. (1962). Disseminated anergic cutaneous leishmaniasis. $\mathrm{Br}$. J. Dermatol. 74, 132-135.

Costa, D. L., Carregaro, V., Lima-Junior, D. S., Silva, N. M., Milanezi, C. M., Cardoso, C. R., Giudice, A., de Jesus, A. R., Carvalho, E. M., Almeida, R. P., and Silva, J. S. (2011). BALB/c mice infected with antimony treatment refractory isolate of Leishmania braziliensis present severe lesions due to IL-4 production. PLoS Negl. Trop. Dis. 5, e965. doi: 10.1371/journal. pntd.0000965

Costa, J. M., Marsden, P. D., LlanosCuentas, E. A., Netto, E. M., Carvalho, E. M., Barral, A., Rosa, A. C., Cuba, C. C., Magalhaes, A. V., and Barreto, A. C. (1986). Disseminated cutaneous leishmaniasis in a field clinic in Bahia, Brazil: a report of eight cases. J. Trop. Med. Hyg. 89, 319-323.

de Moura, T. R., Novais, F. O., Oliveira, F., Clarencio, J., Noronha, A., Barral, A., Brodskyn, C., and de Oliveira, C. I. (2005). Toward a novel experimental model of infection to study American cutaneous leishmaniasis caused by Leishmania braziliensis. Infect. Immun. 73, 5827-5834.

de Moura, T. R., Oliveira, F., Novais, F. O., Miranda, J. C., Clarencio, J., Follador, I., Carvalho, E. M., Valenzuela, J. G., Barral-Netto, M., Barral,
A., Brodskyn, C., and de Oliveira, C. I. (2007). Enhanced Leishmania braziliensis infection following preexposure to sandfly saliva. PLoS Negl. Trop. Dis. 1, e84. doi: 10.1371/ journal.pntd.0000084

de Moura, T. R., Oliveira, F., Rodrigues, G. C., Carneiro, M. W., Fukutani, K. F., Novais, F. O., Miranda, J. C., Barral-Netto, M., Brodskyn, C., Barral, A., and de Oliveira, C. I. (2010). Immunity to Lutzomyia intermedia saliva modulates the inflammatory environment induced by Leishmania braziliensis. PLoS Negl. Trop. Dis. 4, e712. doi: 10.1371/journal. pntd.0000712

de Souza-Neto, S. M., Carneiro, C. M., Vieira, L. Q., and Afonso, L. C. (2004). Leishmania braziliensis: partial control of experimental infection by interleukin-12 p40 deficient mice. Mem. Inst. Oswaldo Cruz. 99, 289-294.

DeKrey, G. K., Lima, H. C., and Titus, R. G. (1998). Analysis of the immune responses of mice to infection with Leishmania braziliensis. Infect. Immun. 66, 827-829.

Falcão, S. C., de Moura, T. R., Clarêncio, J., Brodskyn, C., Barral, A., and de Oliveira, C. I. (2012). The presence of Tregs does not preclude immunity to reinfection with Leishmania braziliensis. Int. J. for Parasitol. (in press).

Faria, D. R., Gollob, K. J., Barbosa, J. Jr., Schriefer, A., Machado, P. R., Lessa, H., Carvalho, L. P., Romano-Silva, M. A., de Jesus, A. R., Carvalho, E. M., and Dutra, W. O. (2005). Decreased in situ expression of interleukin-10 receptor is correlated with the exacerbated inflammatory and cytotoxic responses observed in mucosal leishmaniasis. Infect. Immun. 73, 78537859.

Faria, D. R., Souza, P. E., Duraes, F. V., Carvalho, E. M., Gollob, K. J., Machado, P. R., and Dutra, W. O. (2009). Recruitment of CD8(+) $\mathrm{T}$ cells expressing granzyme $\mathrm{A}$ is associated with lesion progression in human cutaneous leishmaniasis. Parasite Immunol. 31, 432439.

Figueroa, R. A., Lozano, L. E., Romero, I. C., Cardona, M. T., Prager, M., Pacheco, R., Diaz, Y. R., Tellez, J. A., and Saravia, N. G. (2009). Detection of Leishmania in unaffected mucosal tissues of patients with cutaneous leishmaniasis caused by Leishmania (Viannia) species. J. Infect. Dis. 200, 638-646.

Follador, I., Araujo, C., Bacellar, O., Araujo, C. B., Carvalho, L. P., Almeida, R. P., and Carvalho, E. M.
(2002). Epidemiologic and immunologic findings for the subclinical form of Leishmania braziliensis infection. Clin. Infect. Dis. 34, E54-E58.

Gaze, S. T., Dutra, W. O., Lessa, M., Lessa, H., Guimaraes, L. H., Jesus, A. R., Carvalho, L. P., Machado, P., Carvalho, E. M., and Gollob, K. J. (2006). Mucosal leishmaniasis patients display an activated inflammatory T-cell phenotype associated with a nonbalanced monocyte population. Scand. J. Immunol. 63 , 70-78.

Gomes, R., Teixeira, C., Teixeira, M. J., Oliveira, F., Menezes, M. J., Silva, C., de Oliveira, C. I., Miranda, J. C., Elnaiem, D. E., Kamhawi, S., Valenzuela, J. G., and Brodskyn, C. I. (2008). Immunity to a salivary protein of a sand fly vector protects against the fatal outcome of visceral leishmaniasis in a hamster model. Proc. Natl. Acad. Sci. U.S.A. 105, 7845-7850.

Guimaraes-Costa, A. B., Nascimento, M. T., Froment, G. S., Soares, R. P., Morgado, F. N., ConceicaoSilva, F., and Saraiva, E. M. (2009). Leishmania amazonensis promastigotes induce and are killed by neutrophil extracellular traps. Proc. Natl. Acad. Sci. U.S.A. 106, 6748-6753.

Indiani de Oliveira, C., Teixeira, M. J., Teixeira, C. R., Ramos de Jesus, J., Bomura Rosato, A., Santa da Silva, J., Brodskyn, C., Barral-Netto, M., and Barral, A. (2004). Leishmania braziliensis isolates differing at the genome level display distinctive features in BALB/c mice. Microbes Infect. 6, 977-984.

Ives, A., Ronet, C., Prevel, F., Ruzzante, G., Fuertes-Marraco, S., Schutz, F., Zangger, H., Revaz-Breton, M., Lye, L. F., Hickerson, S. M., Beverley, S. M., Acha-Orbea, H., Launois, P., Fasel, N., and Masina, S. (2011). Leishmania RNA virus controls the severity of mucocutaneous leishmaniasis. Science 331, 775-778.

Jones, T. C., Johnson, W. D. Jr., Barretto, A. C., Lago, E., Badaro, R., Cerf, B., Reed, S. G., Netto, E. M., Tada, M. S., Franca, F., Wiese, K., Golightly, L., Fikrig, E., Costa, J. M. L., Cuba, C. C., and Marsden, P. D. (1987). Epidemiology of American cutaneous leishmaniasis due to Leishmania braziliensis braziliensis. J. Infect. Dis. 156, 73-83.

Keesen, T. S., Antonelli, L. R., Faria, D. R., Guimaraes, L. H., Bacellar, O., Carvalho, E. M., Dutra, W. O., and Gollob, K. J. (2011). CD4 (+) $\mathrm{T}$ cells defined by their Vbeta $\mathrm{T}$ cell receptor expression are associated with immunoregulatory profiles and 
lesion size in human leishmaniasis. Clin. Exp. Immunol. 165, 338-351.

Khouri, R., Bafica, A., Silva Mda, P., Noronha, A., Kolb, J. P., Wietzerbin, J., Barral, A., Barral-Netto, M., and Van Weyenbergh, J. (2009). IFN-beta impairs superoxide-dependent parasite killing in human macrophages: evidence for a deleterious role of SOD1 in cutaneous leishmaniasis. J. Immunol. 182, 2525-2531.

Khouri, R., Novais, F., Santana, G., de Oliveira, C. I., Vannier dos Santos, M. A., Barral, A., BarralNetto, M., and Van Weyenbergh, J. (2010). DETC induces Leishmania parasite killing in human in vitro and murine in vivo models: a promising therapeutic alternative in Leishmaniasis. PLoS ONE 5, el4394. doi:10.1371/journal.pone.0014394

Lessa, H. A., Machado, P., Lima, F., Cruz, A. A., Bacellar, O., Guerreiro, J., and Carvalho, E. M. (2001). Successful treatment of refractory mucosal leishmaniasis with pentoxifylline plus antimony. Am. J. Trop. Med. Hyg. 65, 87-89.

Lima, H. C., and Titus, R. G. (1996). Effects of sand fly vector saliva on development of cutaneous lesions and the immune response to Leishmania braziliensis in BALB/c mice. Infect. Immun. 64, 5442-5445.

Lye, L. F., Owens, K., Shi, H., Murta, S. M., Vieira, A. C., Turco, S. J., Tschudi, C., Ullu, E., and Beverley, S. M. (2010). Retention and loss of RNA interference pathways in trypanosomatid protozoans. PLoS Pathog. 6, e1001161. doi: 10.1371/ journal.ppat.1001161

Machado, P., Kanitakis, J., Almeida, R., Chalon, A., Araujo, C., and Carvalho, E. (2002). Evidence of in sittu citotoxicity in American cutaneous leishmaniasis. Eur. J. Dermatol. 12, 449-451.

Maioli, T. U., Takane, E., Arantes, R. M., Fietto, J. L., and Afonso, L. C. (2004). Immune response induced by New World Leishmania species in C57BL/6 mice. Parasitol. Res. 94, 207-212.

Maretti-Mira, A. C., de Pinho Rodrigues, K. M., de OliveiraNeto, M. P., Pirmez, C., and Craft, N. (2011). MMP-9 activity is induced by Leishmania braziliensis infection and correlates with mucosal leishmaniasis. Acta Trop. $119,160-164$.

Maroof, A., Beattie, L., Zubairi, S., Svensson, M., Stager, S., and Kaye, P. M. (2008). Posttranscriptional regulation of II10 gene expression allows natural killer cells to express immunoregulatory function. Immunity 29, 295-305.
Marsden, P. D. (1990). Mucocutaneous leishmaniasis. BMJ 301, 656-657.

Martins, L., Alexandrino, A., and Guimaraes, G. (2010). Detection of Leishmania braziliensis DNA in American tegumentary leishmaniasis patients. Rev. Saude Publica. 44, 571-574.

McFarlane, E., Perez, C., Charmoy, M., Allenbach, C., Carter, K. C., Alexander, J., and Tacchini-Cottier, F. (2008). Neutrophils contribute to development of a protective immune response during onset of infection with Leishmania donovani. Infect. Immun. 76, 532-541.

Mendes-Aguiar Cde, O., Gomes-Silva, A., Nunes, E. Jr., Pereira-Carvalho, R., Nogueira, R. S., Oliveira-Neto Mde, P., Bertho, A. L., and Da-Cruz, A. M. (2009). The skin homing receptor cutaneous leucocyte-associated antigen (CLA) is up-regulated by Leishmania antigens in $\mathrm{T}$ lymphocytes during active cutaneous leishmaniasis. Clin. Exp. Immunol. 157, 377-384.

Mendonca, M. G., de Brito, M. E., Rodrigues, E. H., Bandeira, V., Jardim, M. L., and Abath, F. G. (2004). Persistence of Leishmania parasites in scars after clinical cure of American cutaneous leishmaniasis: is there a sterile cure? J. Infect. Dis. 189, 1018-1023.

Menezes, M. J., Costa, D. J., Clarencio, J., Miranda, J. C., Barral, A., BarralNetto, M., Brodskyn, C., and de Oliveira, C. I. (2008). Immunomodulation of human monocytes following exposure to Lutzomyia intermedia saliva. BMC Immunol. 9, 12. doi: 10.1186/1471-2172-9-12

Miles, S. A., Conrad, S. M., Alves, R. G., Jeronimo, S. M., and Mosser, D. M. (2005). A role for IgG immune complexes during infection with the intracellular pathogen Leishmania. J. Exp. Med. 201, 747-754.

Miranda, J. C., Reis, E., Schriefer, A., Goncalves, M., Reis, M. G., Carvalho, L., Fernandes, O., BarralNetto, M., and Barral, A. (2002). Frequency of infection of Lutzomyia phlebotomines with Leishmania braziliensis in a Brazilian endemic area as assessed by pinpoint capture and polymerase chain reaction. Mem. Inst. Oswaldo Cruz. 97, 185-188.

Norsworthy, N. B., Sun, J., Elnaiem, D., Lanzaro, G., and Soong, L. (2004). Sand fly saliva enhances Leishmania amazonensis infection by modulating interleukin-10 production. Infect. Immun. 72, 1240-1247.

Novais, F. O., Santiago, R. C., Bafica, A., Khouri, R., Afonso, L., Borges, V. M.,
Brodskyn, C., Barral-Netto, M., Barral, A., and de Oliveira, C. I. (2009). Neutrophils and macrophages cooperate in host resistance against Leishmania braziliensis infection. J. Immunol. 183, 8088-8098.

Novoa, R., Bacellar, O., Nascimento, M., Cardoso, T. M., Ramasawmy, R., Oliveira, W. N., Schriefer, A., and Carvalho, E. M. (2011). IL-17 and regulatory cytokines (IL-10 and IL-27) in L. braziliensis infection. Parasite Immunol. 33, 132-136.

Nylen, S., Maurya, R., Eidsmo, L., Manandhar, K. D., Sundar, S., and Sacks, D. (2007). Splenic accumulation of IL-10 mRNA in T cells distinct from CD4+CD25+ (Foxp3) regulatory $\mathrm{T}$ cells in human visceral leishmaniasis. J. Exp. Med. 204, 805-817.

Oliveira, F., Bafica, A., Rosato, A. B., Favali, C. B., Costa, J. M., Cafe, V., Barral-Netto, M., and Barral, A. (2011). Lesion size correlates with Leishmania antigen-stimulated TNFlevels in human cutaneous leishmaniasis. Am. J. Trop. Med. Hyg. 85, 70-73.

Patterson, J. L. (1993). The current status of Leishmania RNA virus I. Parasitol. Today 9, 135-136.

Peacock, C. S., Seeger, K., Harris, D., Murphy, L., Ruiz, J. C., Quail, M. A., Peters, N., Adlem, E., Tivey, A., Aslett, M., Kerhornou, A., Ivens, A., Fraser, A., Rajandream, M. A., Carver, T., Norbertczak, H., Chillingworth, T., Hance, Z., Jagels, K., Moule, S., Ormond, D., Rutter, S., Squares, R., Whitehead, S., Rabbinowitsch, E., Arrowsmith, C., White, B., Thurston, S., Bringaud, F., Baldauf, S. L., Faulconbridge, A., Jeffares, D., Depledge, D. P., Oyola, S. O., Hilley, J. D., Brito, L. O., Tosi, L. R., Barrell, B., Cruz, A. K., Mottram, J. C., Smith, D. F., and Berriman, M. (2007). Comparative genomic analysis of three Leishmania species that cause diverse human disease. Nat. Genet. 39, 839-847.

Pompeu, M. M., Brodskyn, C., Teixeira, M. J., Clarencio, J., Van Weyenberg, J., Coelho, I. C., Cardoso, S. A., Barral, A., and Barral-Netto, M. (2001). Differences in gamma interferon production in vitro predict the pace of the in vivo response to Leishmania amazonensis in healthy volunteers. Infect. Immun. 69, 74537460.

Rebelo, J. M., Assuncao, A. N. Jr., Silva, O., and Moraes, J. L. (2010). Occurrence of sand flies (Diptera, Psychodidae) in leishmaniasis foci in an ecotourism area around the Lencois Maranhenses National Park,
Brazil. Cad. Saude Publica. 26, 195-198.

Ribeiro-de-Jesus, A., Almeida, R. P., Lessa, H., Bacellar, O., and Carvalho, E. M. (1998). Cytokine profile and pathology in human leishmaniasis. Braz. J. Med. Biol. Res. 31, 143-148.

Rocha, F. J., Schleicher, U., Mattner, J., Alber, G., and Bogdan, C. (2007). Cytokines, signaling pathways, and effector molecules required for the control of Leishmania (Viannia) braziliensis in mice. Infect. Immun. 75, 3823-3832.

Rohousova, I., Ozensoy, S., Ozbel, Y., and Volf, P. (2005). Detection of species-specific antibody response of humans and mice bitten by sand flies. Parasitology 130, 493-499.

Ronet, C., Hauyon-La Torre, Y., RevazBreton, M., Mastelic, B., TacchiniCottier, F., Louis, J., and Launois, P. (2010) Regulatory B cells shape the development of Th2 immune responses in $\mathrm{BALB} / \mathrm{c}$ mice infected with Leishmania major through IL10 production. J. Immunol. 184 , 886-894.

Salay, G., Dorta, M. L., Santos, N. M., Mortara, R. A., Brodskyn, C., Oliveira, C. I., Barbieri, C. L., and Rodrigues, M. M. (2007). Testing of four Leishmania vaccine candidates in a mouse model of infection with Leishmania (Viannia) braziliensis, the main causative agent of cutaneous leishmaniasis in the New World. Clin. Vaccine Immunol. 14, 1173-1181.

Samuelson, J., Lerner, E., Tesh, R., and Titus, R. (1991). A mouse model of Leishmania braziliensis braziliensis infection produced by coinjection with sand fly saliva. J. Exp. Med. 173 , 49-54.

Schubach, A., Haddad, F., OliveiraNeto, M. P., Degrave, W., Pirmez, C., Grimaldi, G. Jr., and Fernandes, O. (1998). Detection of Leishmania DNA by polymerase chain reaction in scars of treated human patients. $J$. Infect. Dis. 178, 911-914.

Shi, H., Chamond, N., Tschudi, C., and Ullu, E. (2004). Selection and characterization of RNA interferencedeficient trypanosomes impaired in target mRNA degradation. Eukaryot. Cell 3, 1445-1453.

Sousa Ade, Q., Parise, M. E., Pompeu, M. M., Coehlo Filho, J. M., Vasconcelos, I. A., Lima, J. W., Oliveira, E. G., Vasconcelos, A. W., David, J. R., and Maguire, J. H. (1995). Bubonic leishmaniasis: a common manifestation of Leishmania (Viannia) braziliensis infection in Ceara, Brazil. Am. J. Trop. Med. Hyg. 53, 380-385. 
Stager, S., Maroof, A., Zubairi, S., Sanos, S. L., Kopf, M., and Kaye, P. M. (2006). Distinct roles for IL-6 and IL-12p40 in mediating protection against Leishmania donovani and the expansion of IL-10+ CD4+ T cells. Eur. J. Immunol. 36, 1764-1771.

Svensson, M., Maroof, A., Ato, M., and Kaye, P. M. (2004). Stromal cells direct local differentiation of regulatory dendritic cells. Immunity 21, 805-816.

Tarr, P. I., Aline, R. F. Jr., Smiley, B. L., Scholler, J., Keithly, J., and Stuart, K. (1988). LR1: a candidate RNA virus of Leishmania. Proc. Natl. Acad. Sci. U.S.A. 85, 9572-9575.

Tavares, N. M., Silva, R. A., Costa, D. J., Pitombo, M. A., Fukutani, K. F., Miranda, J. C., Valenzuela, J. G., Barral, A., de Oliveira, C. I., BarralNetto, M., and Brodskyn, C. (2011). Lutzomyia longipalpis saliva or salivary protein LJM19 protects against Leishmania braziliensis and the saliva of its vector, Lutzomyia intermedia. PLoS Negl. Trop. Dis. 5, el169. doi: 10.1371/journal.pntd.0001169

Teixeira, M. J., Fernandes, J. D., Teixeira, C. R., Andrade, B. B., Pompeu,
M. L., Santana da Silva, J., Brodskyn, C. I., Barral-Netto, M., and Barral, A. (2005). Distinct Leishmania braziliensis isolates induce different paces of chemokine expression patterns. Infect. Immun. 73 , 1191-1195.

Thiakaki, M., Rohousova, I., Volfova, V., Volf, P., Chang, K. P., and Soteriadou, K. (2005). Sand fly specificity of saliva-mediated protective immunity in Leishmania amazonensis-BALB/C mouse model. Microbes Infect. 7 760-766.

Trinchieri, G., Pflanz, S., and Kastelein, R. A. (2003). The IL-12 family of heterodimeric cytokines: new players in the regulation of $\mathrm{T}$ cell responses. Immunity 19, 641-644.

Valenzuela, J. G., Belkaid, Y., Garfield, M. K., Mendez, S., Kamhawi, S., Rowton, E. D., Sacks, D. L., and Ribeiro, J. M. (2001). Toward a defined anti-Leishmania vaccine targeting vector antigens: characterization of a protective salivary protein. J. Exp. Med. 194, 331-342.

Vargas-Inchaustegui, D. A., Hogg, A. E., Tulliano, G., Llanos-Cuentas,
A., Arevalo, J., Endsley, J. J., and Soong, L. (2010). CXCL10 production by human monocytes in response to Leishmania braziliensis infection. Infect. Immun. 78, 301-308.

Vargas-Inchaustegui, D. A., Tai, W. Xin, L., Hogg, A. E., Corry, D. B., and Soong, L. (2009). Distinct roles for MyD88 and Toll-like receptor 2 during Leishmania braziliensis infection in mice. Infect. Immun. 77, 2948-2956.

Vargas-Inchaustegui, D. A., Xin, L. and Soong, L. (2008). Leishmania braziliensis infection induces dendritic cell activation, ISG15 transcription, and the generation of protective immune responses. J. Immunol. 180, 7537-7545.

Yoshimura, T., Takeda, A., Hamano S., Miyazaki, Y., Kinjyo, I., Ishibashi, T., Yoshimura, A., and Yoshida, H. (2006). Two-sided roles of IL-27: induction of Th1 differentiation on naive $\mathrm{CD} 4+\mathrm{T}$ cells versus suppression of proinflammatory cytokine production including IL-23-induced IL-17 on activated CD4+ T cells partially through STAT3-dependent mechanism. J. Immunol. 177, 53775385.

Conflict of Interest Statement: The authors declare that the research was conducted in the absence of any commercial or financial relationships that could be construed as a potential conflict of interest.

Received: 14 February 2012; accepted: 18 May 2012; published online: 08 June 2012.

Citation: de Oliveira CI and Brodskyn CI (2012) The immunobiology of Leishmania braziliensis infection. Front. Immun. 3:145. doi: 10.3389/fimmu. 2012.00145

This article was submitted to Frontiers in Microbial Immunology, a specialty of Frontiers in Immunology.

Copyright (c) 2012 de Oliveira and Brodskyn. This is an open-access article distributed under the terms of the Creative Commons Attribution Non Commercial License, which permits non-commercial use, distribution, and reproduction in other forums, provided the original authors and source are credited. 